\title{
Tecnologia e(m) Sala de Aula: oportunidades para (re)conciliar a internet e o trabalho do professor
}

\section{Technology in the Classroom: opportunities to reconcile internet with the work of teachers}

\begin{abstract}
Resumo:
O objetivo do texto é levantar discussão sobre modos de a tecnologia comparecer em sala de aula como uma aliada dos professores em suas práticas pedagógicas. Damos ênfase ao uso da internet e abordamos formas de explorar seu potencial de maneira que o professor conduza o processo de ensino-aprendizagem pela aproximação com a realidade que o estudante de hoje experimenta. Trazendo reflexões como a de Tornaghi (2010) sobre tecnologia na escola e de Ninim (2008) sobre o papel da pesquisa na sala de aula, discutimos oportunidades de envolver os estudantes pelo recurso à internet nas aulas de Língua Portuguesa e nas atividades de pesquisa escolar em geral, exemplificando e defendendo o papel de mediador que o professor exerce nessa nova configuração.

Palavras-chave: Novas tecnologias. Internet. Língua portuguesa - Ensino. Prática de pesquisa.
\end{abstract}

\begin{abstract}
:
This article aims to discuss beneficial ways of introducing technology into classrooms as an ally for teachers in their teaching practices. We emphasize internet use and address ways of exploring its potential to allow teachers to bring the teaching-learning process closer to the student's reality. Bringing reflections as Tornaghi (2010) on technology in the school and Ninim (2008) on the role of the research in the classroom, we discuss opportunities to engage students by using the internet in Portuguese classes and general school research activities, exemplifying and defending the teacher's role as a mediator in this new setting.

Keywords: Technology. Internet. Portuguese - Teaching.
\end{abstract} School research.

BRAGA, Diego Vieira; MARRONI, Fabiane Villela; FRANCO, Patricia Pereira. Tecnologia e $(m)$ Sala de Aula: oportunidades para (re)conciliar a internet e o trabalho do professor. Informática na Educação: teoria e prática, Porto Alegre, v. 18, n. 2, p. 199-210, jul./dez. 2015.

\section{Diego Vieira Braga}

Fabiane Villela Marroni

\section{Patricia Pereira Franco}

\section{Introdução}

$H^{2}$ á muitas maneiras de compreender a tecnologia, já que podemos relacioná-la a diferentes áreas do conhecimento. Podemos caracterizá-la como domínios, ofícios, instrumentos que são utilizados no dia a dia da atividade humana. Portanto, na atualidade, o que nos parece, de certa forma, um senso comum, é que a tecnologia vem auxiliar e facilitar a vida do ser humano.

Quando pensamos em tecnologia no ambiente escolar, sabemos que não se resume apenas ao uso de um equipamento como o computador. No entanto, neste texto, a tecno- 
logia a que faremos referência é a do uso da internet, seja em computadores, tablets, celulares ou afins. Ou seja, a tecnologia/internet como ferramenta no processo de ensino-aprendizagem.

Partimos do entendimento que os recursos tecnológicos devem funcionar em sala de aula como um meio de aproximação entre alunos e professores. A internet é percebida aqui como exemplar nesse funcionamento, pois oferece condições de ganhos mútuos de aprendizagem na relação aluno-professor, considerando sua compatibilidade com os novos rumos da educação, com a ênfase no aluno e em sua ação como sujeito, conforme já destacava Sobral (1999). Além de aventar contribuições para a motivação do aluno e para a facilitação das tarefas do professor, o autor salienta que a internet tem seu lugar na educação porque, ao intervir no contato do aluno com o mundo, tornando-o mais direto, atende a necessidade - que se mantém atual - de uma "[...] experiência direta como modalidade de aprendizagem mais propícia ao desenvolvimento da capacidade de resolução criativa de problemas [...]" (SOBRAL, 1999, p. 15).

Torna-se válido, portanto, considerar que as chamadas novas tecnologias ou Tecnologias da Informação e Comunicação (TICs) podem aprimorar o processo de ensino-aprendizagem, compreensão que faz com que seja sempre pertinente discutir aspectos como a desconfiança ou insegurança que o professor pode sentir ao pensar como melhor aproveitar esses novos recursos em sua atividade. No caso da internet, na forma como será abordada neste texto, somos levados a pensá-la enquanto ferramenta de apoio para o professor e não como mera substituta de outros instrumentos didáticos como livros, por exemplo.

Nossas inquietações podem ser sintetizadas em duas questões gerais: a) como transformar a tecnologia em uma aliada?; e, b) como mostrar aos professores que a internet pode colaborar no processo de ensino-aprendizagem e que sua presença em sala não está vinculada, necessariamente, à dispersão da atenção do aluno ou à busca por respostas rápidas e acríticas? O que proporemos ao longo do texto poderá ser interpretado como ideias, sugestões, mas não temos a pretensão de fornecer respostas aplicáveis indistintamente, desconsiderando diferentes circunstâncias e singularidades que constituem o espaço de uma sala de aula. Sem entrar nesse mérito, gostaríamos sim de discutir possibilidades de trabalho para o professor a partir da compreensão da internet como uma aliada, apresentando, como oportunidades exemplares, as aulas de Língua Portuguesa e a realização de atividades de pesquisa escolar.

\section{Pensando o Uso da Internet em Aulas de Língua Portuguesa}

Vivemos em uma sociedade que valoriza o uso de novas tecnologias e, cada vez mais, a convivência nos espaços digitais e, por isso, torna-se praticamente impossível ficarmos alheios à presença da internet e aos equipamentos que nos conectam a ela. No dia a dia, vemos pessoas utilizando, a todo o momento e nos mais diferentes lugares, celulares, smartphones, tablets, computadores, enfim, tudo o que venha facilitar o acesso e garantir a manutenção de nossas conexões, quase em tempo integral.

O momento é histórico, já que nunca as pessoas recorreram tanto às TICs e, em especial, à internet, como auxílio para a realização das mais variadas funções e mesmo como meio principal para se comunicarem, trabalharem, entreterem-se etc. Aos nascidos a partir 
do início dos anos 90, costuma-se associar a expressão nativo digita/ ${ }^{1}$. E isso não é por acaso. A todo o momento, vemos a facilidade com que as crianças e adolescentes manuseiam seus celulares e afins, explorando, com uma familiaridade que impressiona, diferentes formas de se comunicarem e de se expressarem por meio da conexão com a rede.

Pode-se perceber o quanto a sociedade do século XXI está impregnada pelas novidades tecnológicas que surgem ou são incrementadas ano a ano. No caso de tecnologias relativas ao mundo digital, se nos é permitida uma comparação, diríamos que são como um vírus: espalham-se sem pedir licença e quando percebemos, já estamos infectados. Isso faz com que diferentes âmbitos como o cultural, o político, o educacional, entre outros, sejam afetados. Não há como ficar imune e no ambiente escolar não é diferente.

Alunos parecem não conseguir deixar de manusear seus telefones que quase tudo fazem: ligações, envio de SMS, acesso à internet e ao já famoso WhatsApp $\AA$ bem como outros tantos aplicativos e/ou sites de relacionamento. Dessa forma, professores se encontram diante de uma difícil tarefa: como despertar a atenção de seu aluno, sendo que, não raras vezes, a própria escola se encontra menos equipada que o estudante no que concerne ao acesso a novos recursos tecnológicos. Mas tão ou mais preocupantes são os casos de instituições que, mesmo dispondo dos recursos técnicos relativos às TICs, não os empregam de modo satisfatório no processo de ensino-aprendizagem, não exploram seu potencial

\footnotetext{
${ }^{1}$ É prudente fazer a ressalva de que o emprego desse termo pode fomentar a ideia de que a tecnologia está disponível para todos, em todo lugar, desde o nascimento. Em que pese esforços em diferentes esferas da sociedade, no sentido de se promover uma maior inclusão digital da população, há ainda muitos lugares e situações em que o termo nativo digital só pode ser parcialmente afirmado.
}

nem aproveitam a própria familiaridade que o estudante demonstra com o meio.

Gostaríamos de remeter a um texto intitulado O que a Escola Faz Com a Tecnologia? O que a Tecnologia Faz Com a Escola? e publicado na edição de março/abril de 2010 da revista TV Escola, em que o pesquisador Alberto Tornaghi (2010) analisa aspectos referentes a maneiras de trazer a internet para a sala de aula, isto é, como o professor pode utilizar essa ferramenta no processo de ensino-aprendizagem. Suas sugestões podem ser compreendidas como um incentivo para que o professor comece a perceber a pertinência e a riqueza de um trabalho pautado pela experimentação, pela colaboração e, não menos importante, pelo interesse que as tecnologias digitais despertam nos alunos.

Uma dessas sugestões está na utilização da Wikipédia ${ }^{\circledR}{ }^{2}$. Muitos professores, e até usuários da internet, criticam esse site de aparência enciclopédica pelo fato de receber textos de diferentes pessoas, o que tornaria o conteúdo pouco confiável. Para Tornaghi (2010), o fato de existir uma espécie de revisão que antecede a publicação efetiva do conteúdo, em que outros usuários colaboradores podem revisar e certificar as informações que se pretende incluir, já contribui para um maior controle do que pode ou não ser publicado. Em nossa perspectiva, acrescentaríamos que essa questão não impede que se recorra a esse site nas aulas de Língua Portuguesa do ponto de vista da possibilidade de criação e envio de textos, característica que o torna um espaço apropriado para trabalhar a produção textual dos alunos. O professor pode considerar um assunto e/ou tema que seja relevante para a turma e interessante para publicar no referido site e propor a montagem de um ou mais textos com os alunos visando sua publicação.

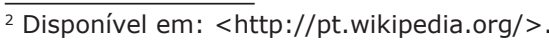


Outra forma de publicação na Wikipédia ${ }^{\circledR}$ são os verbetes. Muitas vezes, em sala de aula, deparamo-nos com alunos que desconhecem várias palavras bem como as diferenças de sentido que aparecem, por exemplo, em um texto que o professor venha a trazer para discussão ou em textos dos próprios livros didáticos. Nesse momento de dúvida com relação aos sentidos que as palavras podem apresentar, é possível unir o uso do dicionário, muitas vezes esquecido e pouco utilizado em sala de aula, com a internet.

A ideia é que os possíveis sentidos para a(s) palavra(s) em questão sejam, em primeira instância, verificados nos dicionários para que depois os alunos possam remetê-la(s) à Wikipédia ${ }^{\circledR}$. Assim, possibilitamos que o aluno manuseie um livro, o dicionário, amplie seu vocabulário bem como as acepções e situações de variação de sentido dos termos e, ao mesmo tempo, explore a tecnologia a partir de um novo ângulo: não mais como mero consultor do conteúdo, mas como produtor deste.

Outra possibilidade que gostaríamos de levantar seria a criação de blogs, páginas que os próprios usuários podem manter na internet por meio de ferramentas disponíveis online, o que não demanda muito tempo ou esforço técnico de criação e atualização. Reconhecemos que grande parte dos alunos tem dificuldade em escrever, e isso parece diretamente relacionados à falta de leitura - tema que abordaremos mais adiante neste texto $-\mathrm{e}$, em alguns casos, também pela falta de interesse e estímulo dos alunos. Pedir para que escrevam redações, artigos, pode ser exaustivo para eles. Então é interessante começar com parágrafos, poesias, músicas, notícias, artigos de opinião, ou seja, diferentes gêneros textuais, tendo a finalidade de tentar despertar no aluno o prazer pela escrita.
Com a criação de um blog, o aluno pode se sentir mais a vontade com a escrita, uma vez que pode publicar diversos tipos textuais. A notícia é um tipo textual bastante interessante de se começar. Alunos parecem sempre dispostos a compartilhar novidades e muitos não esperam a hora do intervalo para se atualizarem uns com os outros. Então, nesta perspectiva, é interessante deixar que relatem algo vivido por eles através de um texto em forma de notícia, por exemplo. Escrever em uma foIha de papel, entregar ao professor e ficar esperando uma nota pelo texto já não é mais interessante à juventude do século XXI. Por isso, a ideia do blog. Com essa proposta, é possível que o professor se detenha na vontade do aluno em escrever, e não somente em devolver o texto do aluno apontando apenas seus erros. Importante salientar que, nessa proposta, os textos produzidos pelos alunos também devem passar pelo olhar do professor de modo que o texto a ser publicado seja aprimorado e o aluno se sinta valorizado.

Alguns dos grandes concorrentes do professor pela atenção do aluno em sala de aula são os sites de rede social, em especial, o Facebook $®$. Grande parte dos alunos, hoje, tem acesso ao site pelo celular, e agem como se essa conexão fosse uma necessidade vital: impossível passar uma aula sequer sem visualizar o perfil, inteirando-se das últimas publicações. Assim, instaura-se o que podemos designar como pseudoguerra: alunos conectados a todo o momento e professores sem saber o que fazer para que isso não aconteça. Entendemos que o pedido para que se desligue o celular não é suficiente nem produtivo. Não é interessante lutar contra a internet ou, especificamente, o Facebook $($ : 0 adequado seria tentar integrá-los às atividades.

No Facebook@, por exemplo, é possível pensar na criação de grupos, que podem ser 
fechados ou abertos, para publicação de textos escritos pelos alunos ou, de outros textos, vídeos que possam ser debatidos através do site de relacionamento. A proposta é fazer uma interação entre conhecimento, alunos, professores e a internet. A internet também pode ser uma aliada no que diz respeito à leitura. É fato que a juventude de hoje pouco se interessa por livros, pela leitura de uma forma geral. E a falta de leitura proporciona problemas não só para a escrita, mas também para a criticidade de cada um.

Está cada vez mais difícil fazer com que nossos alunos leiam. Em geral, tudo que é proposto aos alunos para leitura é considerado desinteressante seja porque o livro Ihes parece muito extenso e, por isso, dá preguiça de ler (para usar uma expressão recorrente para muitos alunos) seja porque o tema não seria atrativo. Pedir para que o aluno leia um livro inteiro pode se converter em uma proposta improdutiva. Então, é essencial que se comece aos poucos, com parágrafos, pequenas notícias e/ou reportagens que sejam interessantes a eles. E, mais uma vez, o professor pode se valer da internet para tornar a atividade mais instigante. A proposta é que os alunos procurem textos, assuntos de seu interesse e dediquem um tempo para a leitura. O professor pode disponibilizar esse tempo em suas aulas ou pedir para que os alunos façam isso em casa e que, depois, debatam o texto lido em sala de aula.

Também é possível pedir aos alunos que, após terem lido o texto escolhido, façam comentários. É uma forma de o aluno começar a se expressar criticamente: primeiro a partir de materiais de seu interesse, que o instiguem mais naturalmente a essa reflexão, depois, com outros textos introduzidos pelo professor que, aproveitando-se dessa disposição inicial, amplia o leque de temas e conteúdos a serem debatidos de maneira crítica. Podemos pensar, também, nos sites de compartilhamento de vídeos, como outra ferramenta didática, sendo o Youtube $\AA$ aparentemente o mais acessível e certamente o mais conhecido deles. Os alunos podem gravar vídeos, orientados pelo professor, em sala de aula. Esses vídeos podem ter temáticas variadas como dicas de conteúdos gramaticais - ortografia, concordância, regência, entre outros - ou, ainda, dicas para provas de vestibulares ou para o Exame $\mathrm{Na}$ cional do Ensino Médio (ENEM), entre outras possibilidades não só na disciplina de Língua Portuguesa, que destacamos no presente texto, como em outros componentes curriculares.

O importante é que a internet não seja vista como uma obrigatoriedade didática em sala de aula, mas que seja compreendida como uma ferramenta de inter-relação e de apoio para o professor no desenvolvimento das atividades propostas aos alunos. Ampliando nossa discussão, abordamos a seguir o uso da internet em relação a uma das práticas mais tradicionais, a pesquisa escolar.

\section{Pensando o Uso da Internet e a Prática da Pesquisa na Escola}

Pesquisar é uma das atividades que mais tem se transformado com o desenvolvimento e popularização das novas tecnologias. Para os estudantes, recorrer a volumosas (e onerosas) fontes materiais é uma prática que parece soar anacrônica se considerarmos a profusão de informações sobre os mais variados temas, acessíveis, hoje, por meio de alguns poucos toques em uma tela, bem como na palma de nossas mãos.

O fato é que os professores já lidam com a passagem da pesquisa do meio impresso para o digital e o primeiro desafio, ou oportunidade, 
que tal transição suscita é o próprio repensar dessa atividade em sala de aula. Retornamos ao artigo de Tornaghi (2010), a respeito do uso que a escola faz das tecnologias digitais, para refletir um pouco sobre o ponto de vista do autor para uma das principais queixas de educadores a respeito do uso da internet como fonte de pesquisa e informações. Conforme suas palavras:

É recorrente a reclamação de alunos que apenas copiam e colam informações da internet e apresentam os textos como trabalhos seus. Não há dúvida de que isso acontece, mas não é diferente do que ocorria, com frequência, nos tempos das enciclopédias em papel. Em que sentido a internet nos permite ir além disso? (TORNAGHI, 2010, p. 24)

Desta forma, se espera sensibilidade do professor para identificar contribuições dos novos recursos para antigas discussões como as que envolvem práticas de pesquisa e a produção autoral, questão relevante levantada por Tornaghi. No caso da internet, o autor crê que esta possa contribuir para que a pesquisa escolar "[...] se transforme em processo de criação real e de autoria [...]" (TORNAGHI, 2010, p. 24). Como exemplo, sugere que seja proposta aos alunos a criação de um texto que consista exatamente em uma colagem de trechos de outros textos, sob a condição de que não sejam todos obtidos na mesma fonte, e apresentando as devidas citações. Segundo o autor, a necessidade de produzir um texto que tenha sentido com base em conteúdos de múltiplas fontes exigirá que os alunos se posicionem criticamente na leitura e seleção das informações consultadas. Ao comentarem e explicarem suas escolhas, os alunos estarão materializando sua leitura crítica e, como completa Tornaghi (2010, p. 24), "[...] experimentando um pouco o que é a vida do cientista $[\ldots]$ ".
Convém salientar que um procedimento como esse exige que o professor supere as desconfianças que são costumeiramente associadas ao trabalho de pesquisa por meio da internet no contexto escolar. Sobre esse aspecto, identificamo-nos com a reflexão de Bernardes e Fernandes (2005). Em estudo sobre a pesquisa escolar diante da difusão das novas tecnologias, particularmente da internet, as autoras problematizam precisamente a questão da cópia no texto da pesquisa a partir da perspectiva da teoria enunciativa de Bakhtin. Para elas, pesquisar na internet consiste em um ato de linguagem do aluno que não deve ser visto pelo professor como mera reprodução de informações. O processo da pesquisa com o apoio da internet se efetiva "[...] a partir de uma leitura que, ao invés de dissolver-se nas infinitas possibilidades trazidas pelo hipertexto, caracteriza-se por uma busca consciente de informações [...]" (BERNARDES; FERNANDES, 2005, p. 134). O motivo é a própria natureza do meio, caracterizado pela interconectividade, pelas correlações entre conteúdos que estimulam aquele que pesquisa a construir um percurso próprio de leitura. Essa configuração possibilita uma "[...] recontextualização dialógica dos sentidos [...]" (BERNARDES; FERNANDES, 2005, p. 134) por parte do aluno, um leitor-navegador como designam as autoras. Concordamos com Bernardes e Fernandes pelo fato que os professores que consideram o texto de pesquisa desenvolvido com o apoio da internet mera cópia por parte do aluno não percebem que se materializa sim um "[...] percurso de leitura na rede, ou seja, nas páginas ali impressas o aluno apresenta um texto construído em co-autoria com outros autores, como resultado de sua busca no meio virtual [...]" (BERNARDES; FERNANDES, 2005, p. 134-135). 
As reflexões que embasam nosso posicionamento manifestam a predisposição de compreender a internet não como mero suporte no processo de aprendizagem, mas, ao contrário, uma aliada no exercício de competências e habilidades a serem desenvolvidas. Um ponto de vista que não se pode afirmar que seja compartilhado pela maioria dos profissionais da educação, pois influenciam nessa compreensão diversos fatores que vão da falta de conhecimento técnico sobre o uso e possibilidades dos recursos disponíveis ao papel que acreditam terem de desempenhar com relação à pesquisa.

Segundo Ninim (2008), em estudo que aborda o tema da pesquisa escolar sob a perspectiva da pedagogia crítica, a atividade da pesquisa "[...] nem sempre cumpre seu papel em relação ao desenvolvimento do pensamento crítico e à construção de conhecimentos [...]" (NINIM, 2008, p. 18). Para a autora, pesquisa escolar é a atividade "[...] sistematizada e mediada entre sujeitos, pautada em instrumentos que propiciam a construção do conhecimento e o desenvolvimento da autonomia, por meio de ações com características de reflexão crítica [...]" (NINIM, 2008, p. 21). Nesse tipo de atividade, além da já mencionada dificuldade em lidar com a propensão dos alunos de comporem seus textos com fragmentos de outros sem qualquer reflexão própria, a autora atribui à conduta dos professores uma parte da responsabilidade pela pesquisa escolar não resultar em uma atividade pedagogicamente produtiva.

Para Ninim (2008), ainda nos dias de hoje, grande parte dos professores mantêm o procedimento de oferecer aos alunos um roteiro para o desenvolvimento da referida atividade, em que se estabelece data de entrega, solicitam-se os nomes dos alunos (caso seja permitida a realização em grupo) e são indicadas tanto as partes em que o trabalho deve estar dividido (introdução, objetivo, justificativa, etc.) quanto os conteúdos a serem pesquisados. Como orientação, completa a autora, acrescentam-se algumas dicas, tais como "[...] 'não faça cópia de trechos de livros', 'a entrega do trabaIho fora do prazo implica diminuição na nota', entre outras [...]" (NINIM, 2008, p. 18). Esta e outras formas habituais de conduzir as atividades em sala de aula podem colocar o trabaIho do professor em modo automático. Nesses casos, é provável que o professor só volte a intervir na ocasião da entrega do trabalho, realizando a correção e a atribuição das notas.

Compartilhando da perspectiva da autora, pode-se perceber que é fundamental que o professor considere a importância de sua presença durante a elaboração da pesquisa, de modo que seja percebido como mediador no processo. O professor que se apresenta como "[...] um parceiro na construção do conhecimento $[\ldots]$ ", para usar as palavras de Ninim (2008, p. 20), ressignifica uma percepção convencional sobre a prática da pesquisa em sala de aula, já que ao invés de solicitar conteúdos específicos, bem como definir a forma e os locais onde pesquisá-los, ele "[...] oferece indicações 'abertas' que instigam a curiosidade dos alunos em relação ao assunto estudado [...]" (NINIM, 2008, p. 20).

A preocupação do professor não pode se resumir a determinações prévias e à rigorosa conformidade do trabalho final a elas, mas com a atenção e o acompanhamento permanentes em etapas intermediárias, o que implica discussões, reorientações e ajustes. Ainda, segundo Ninim (2008), o professor deve oferecer momentos durante o andamento da atividade para discutir com os alunos o que estes já produziram. A autora adverte que essa intervenção não pode consistir somente em uma olha- 
da no trabalho, mas em uma mediação capaz de " [...] gerar conflitos para que os alunos façam novas buscas, sintam-se intrigados com suas próprias conclusões, duvidem do que já produziram e recorram a novos caminhos [...]" (NINIM, 2008, p. 29). Certamente, uma postura como essa contribui para que a pesquisa em sala de aula seja valorizada menos por consequências cumulativas e mais pelos resultados qualitativos relacionados ao desenvolvimento dos alunos. Isso apoiados no entendimento de que a pesquisa não pode ser percebida pelos alunos apenas como uma atividade para alcançar ou aumentar a média de notas ou, pelos professores, como uma maneira de complementar ou antecipar conteúdos conforme relatado por Oliveira et. al. (apud NINIM, 2008, p. 24).

Compreendemos que tais percepções permanecem devido à prática que vigora ainda hoje na maioria das escolas que é a do exame e não a da avaliação, conforme distinção feita Luckesi (2004, 2006). Para esse autor, o exame é

[...] classificatório (coloca o estudante em um nível específico de uma escala), seletivo (a partir da posição na qual o estudante é classificado, é aprovado ou reprovado), antidemocrático (se há seletividade, não pode ser democrático, a aprendizagem seria para poucos) e autoritário (quem decide é somente a autoridade e sempre do seu ponto de vista) $[. .$.$] (LUCKESI, 2006).$

Já a avaliação, na concepção desse autor, diferencia-se do exame por se caracterizar como

[...] diagnóstica (investiga o nível de desempenho do educando e seus impasses), inclusiva (reorienta o estudante a partir do diagnóstico realizado, sempre incluindo-o na aprendizagem satisfatória), democrática (se ela é inclusiva, deseja que todos aprendam, não somente uns poucos) e dialógica (há diálogo no processo avaliativo; nem sempre a autoridade tem razão) [...] (LUCKESI, 2006).

Levando em consideração essa distinção, a função da pesquisa, portanto, deve ser dirigida sob a ótica da avaliação, o que significa, retomando o que diz o autor em outro texto, "[...] subsidiar a construção do melhor resultado possível e não pura e simplesmente aprovar ou reprovar alguma coisa [...]" (LUCKESI, 2004). Ainda segundo o autor, para tornar isso possível, o professor pode fazer uso dos instrumentos técnicos disponíveis atualmente, desde que se certifique que "[...] a leitura e interpretação dos dados seja feita sob a ótica da avaliação, que é de diagnóstico e não de classificação [...]" (LUCKESI, 2004).

Com o que expomos até o momento, fica evidente que as tecnologias, consideradas indispensáveis em nosso dia a dia, têm um papel concernente às expectativas atuais da educação. Cabe ao professor reconhecer possibilidades de articulação, pensando de que maneira os recursos disponíveis - inclusive, como comentamos inicialmente, aqueles provenientes dos próprios alunos como, por exemplo, smartphones e tablets - podem ser utilizados produtivamente no desenvolvimento de suas aulas e de atividades como a pesquisa, sem deixar que os instrumentos ocupem seu lugar de mediador na aprendizagem.

Além disso, articulando com o pensamento de Valente (1998) em um livro considerado clássico sobre a contribuição do computador no processo de aprendizagem, a grande questão que se coloca é como a informática na educação pode transformar a própria pedagogia da escola: de uma visão centrada na transmissão de informações para outra que in- 
centive os alunos a buscarem e selecionarem o conhecimento, de modo que, acrescentamos, seja promovida sua autonomia.

Sabemos, portanto, que a relação das novas tecnologias com a pesquisa (e a educação em geral) que é praticada nas escolas depende, por um lado, da forma como são utilizados os recursos disponíveis e, por outro, do envolvimento e comprometimento do professor durante todo o processo. Levando em conta essas condições, partimos para a reflexão sobre o desafio para o educador de conciliar o que as TICs oferecem com os objetivos educacionais, no caso, a internet como fonte de informações e a sua articulação com o desenvolvimento de competências e habilidades dos alunos por meio da atividade de pesquisa. Nesse sentido, discutiremos de forma breve algumas implicações para a educação quanto ao uso de sites de buscas, a partir de seu principal expoente.

\section{Google e as Atividades de Pes- quisa em Sala de Aula}

Cremos ser possível afirmar que a transição de que falamos inicialmente, da prática da pesquisa em fontes impressas para a prática da pesquisa no espaço digital, se deve em grande parte ao surgimento e popularização de um website em especial: o Google ${ }^{\circledR}$. Este nome, pode-se dizer, tornou-se praticamente um sinônimo de como e onde fazer pesquisa na rede. Certas expressões já se tornaram bastante conhecidas por fazerem alusão a sua grande difusão e presença no cotidiano: procura no Google $₫$, joga no Google $\AA$, entre outras.

Por isso, hoje em dia, quando o professor propõe que os alunos façam uma pesquisa, em geral, o primeiro passo - muitas vezes o único passo - é jogar no Google $®$ e coletar o que aparece entre as respostas que elenca. Desse modo, se hoje em dia a aprendizagem é cada vez mais mediada pelo computador, esse processo também contempla a mediação de sites de busca e, entre eles, certamente, o Google $\AA$ é a principal referência. Assim, devemos estar cientes de que essa mesma aprendizagem acaba sendo, de certa forma, mediada pelo Google ${ }^{\circ}$, daí a necessária intervenção do professor para que os alunos não se satisfaçam com qualquer resposta fornecida pelo mecanismo de busca, o que tornaria a atividade improdutiva principalmente a respeito do conhecimento que deveria ser construído, questionado.

É fato que se, hoje, temos mais informação disponível do que nunca sobre uma ampla variedade de assuntos, também nunca foi tão necessário selecionarmos entre essa gama de possibilidades o que realmente vai ao encontro de nossos objetivos. E nesse aspecto temos de nos valer de estratégias para encontrar resultados mais precisos e compatíveis com os objetivos pretendidos. Nesse sentido, o próprio Google ^ lançou em 2012 um novo serviço dirigido ao ensino e aperfeiçoamento de buscas: o Google Search Education ${ }^{3}$ (GSE).

O GSE tem um objetivo aparentemente simples: ensinar a pesquisar melhor. Por meio de videoaulas acessíveis no site da iniciativa, são disponibilizadas dicas para encontrar conteúdos que mais se relacionam com o que procuramos, especialmente através da melhor adequação na escolha das palavras-chave da pesquisa ou da localização de conteúdos mais relevantes ao se reduzir a abrangência de resultados. Assim, o professor pode, por exemplo, trabalhar com a turma a identificação de termos que tornarão suas pesquisas mais

${ }^{3}$ Disponível em: <http://www.google.com/insidesearch/searcheducation/index.html $>$. 
precisas, descobrindo fontes que melhor atendam as expectativas de seu planejamento bem como as dúvidas e discussões surgidas no decorrer do trabalho produzido pelos alunos. Não podemos esquecer que, como compartilhado anteriormente das reflexões de Luckesi (2004, 2006), a atividade de pesquisa, sob a perspectiva da avaliação, é pautada pelo diagnóstico e reorientações permanentes.

Continuando a articular com o debate que vínhamos desenvolvendo, fica claro que uma iniciativa como o GSE traz implicações para a educação, pois o professor, em sua posição de mediador, deve ter como uma de suas preocupações ajudar os alunos a filtrar as informações que nos dias de hoje se avolumam. A questão, que também já antecipamos, é que isso não pode ser feito de uma maneira normativa. Indicar maneiras de melhoria das habilidades de busca não significa impor determinações de onde e como pesquisar. É orientar, apontar caminhos, sempre questionando junto com os educandos a pertinência e potencial das fontes que forem sendo consultadas desde o momento da procura destas, de modo a permitir que se reconheça o caráter decisivo de aspectos aparentemente triviais como o da escolha dos elementos lexicais digitados na barra de pesquisa.

Porém, em nosso entendimento, não se trata apenas de uma mera capacitação do aluno, no sentido de torná-lo acima de tudo tecnicamente eficaz em suas pesquisas. Um recurso como o GSE viabiliza sim esse aperfeiçoamento, mas se isso não for acompanhado de um desenvolvimento da capacidade argumentativa do aluno, todo o esforço para o melhor aproveitamento da tecnologia pode ser em vão. Sem falar que estratégias assim também podem especificar demasiadamente os resultados, tornando-se talvez muito restritivas ou mesmo excludentes, limitando as possibilida- des de discussão sobre diferentes conteúdos relacionados ao que tema pesquisado.

Sob essa perspectiva, pensamos que, sendo o Google $\AA$ uma sofisticada ferramenta de busca, necessitamos de uma certa habilidade para manuseá-la para que o resultado que desejamos construir seja alcançado. Mas devemos estar cientes de que, por mais que refinemos nossa forma de consulta, a recuperação de determinadas informações e conteúdos é proveniente basicamente de um tratamento maquínico. E nunca é demais lembrar que, antes de ser um site, o Google $®$ é uma empresa, uma gigante multinacional, que oferece uma série de serviços e produtos. Neste ponto, cabe acompanhar a ressalva feita por Demo. Diz o autor

[...] tenho dúvidas se o ciberespaço é mundo tão livre assim, já que também está formatado numa infra-estrutura tecnológica linear e física, além de mercadológica liberal, por mais que os raios de liberdade sejam incrivelmente maiores. Não podemos fazer o que bem entendemos, mas o que os equipamentos softwares e hardwares - permitem-nos no contexto das constrições político-ideológicas. Dependendo das habilidades informáticas, a leitura pode se alargar de maneira surpreendente, do que não segue, necessariamente, que seja contraleitura (DEMO, 2007, p. 34, grifos do autor).

Para concluir, concordando com a reflexão do autor, acreditamos que é preciso discernimento ao lidar com a tecnologia, tanto em nossa vida social diária quanto em locais como a escola, afinal a simples disponibilidade de equipamentos eletrônicos e outros recursos tecnológicos não garante, por si só, transformações no processo de ensino-aprendizagem. 


\section{Considerações Finais}

É mais um grande desafio que se coloca ao professor: interpretar o papel da internet e dos instrumentos que permitem acessá-la, a forma com que exploramos esse potencial, sem perdermos de vista nossa iniciativa própria. Em outras palavras, nem dependente, nem indiferente diante de uma profusão de informações a que temos acesso através daqueles poucos toques em uma tela que evocamos no início.

O professor precisa trabalhar de modo que seus alunos percebam a importância de produzirem concepções críticas diante do que estão diariamente e facilmente expostos. Logo, seu papel em sala de aula, enquanto mediador do processo, não se reduz, não se dilui em meio às possibilidades oferecidas pelo avanço da tecnologia. Ao contrário, sua presença acaba sendo valorizada exatamente pela demanda, pela necessidade de reorientações contínuas frente ao que a tecnologia pode fornecer.

No caso do uso da internet, as alternativas levantadas quanto a sua participação no desenvolvimento das aulas de Língua Portuguesa e das atividades de pesquisa se apresentam, em nosso entender, como oportunidades exemplares de conciliação entre tecnologia e trabalho pedagógico e de consolidação da relação aluno-professor. São exemplos que permitem trabalhar, em um mesmo exercício, o melhor domínio sobre o conhecimento técnico, uma leitura mais compreensiva, à altura do potencial educativo da rede, o estímulo ao reconhecimento do professor nesse novo contexto e a autonomia do aluno frente às tecnologias que já estão fortemente integradas a sua vida.

\section{Referências}

BERNARDES, Alessandra Sexto; FERNANDES, Olívia Paiva. A Pesquisa Escolar em Tempos de Internet. In: FREITAS, Maria Teresa de Assunção; COSTA, Sérgio Roberto (Org.). Leitura e Escrita de Adolescentes na Internet e na Escola. Belo Horizonte: Autêntica, 2005. p. 117-136.

DEMO, Pedro. O Porvir: desafios das linguagens do século XXI. Curitiba, PR: Ed. IBPEX, 2007.

LUCKESI, Cipriano. Considerações Gerais Sobre Avaliação no Cotidiano Escolar: [entrevista] Aprender a Fazer, Curitiba, n. 36, p. 4-6, 2004. Disponível em: <http://www.luckesi.com.br/artigosavaliacao. htm> Acesso em: 18 jun. 2014.

LUCKESI, Cipriano. [Entrevista]. Folha Dirigida, Rio de Janeiro, n. 1069, 06 out. 2006. Caderno Aprender, p. 9. Disponível em: <http://www.luckesi.com.br/artigosavaliacao.htm> Acesso em: 18 jun. 2014. 
NINIM, Maria Otilia Guimarães. Pesquisa na Escola: que espaço é esse?: o conteúdo ou o do pensamento crítico? Educação em Revista, Belo Horizonte, n. 48, p. 17-35, dez. 2008. Disponível em: <http:// www.scielo.br/scielo.php?script=sci_arttext\&pid=S0102-46982008000200002> Acesso em: 16 maio 2014.

SOBRAL, Adail. Internet na Escola: o que é, como se faz? São Paulo: Loyola, 1999.

TORNAGHI, Alberto. O que a Escola Faz com a Tecnologia?: e o que a tecnologia faz com a escola? Revista TV Escola: tecnologias na educação, Curitiba, n. 1, p. 24-25, mar./abr. 2010. Disponível em: <portaldoprofessor.mec.gov.br/storage/materiais/0000013961.pdf> Acesso em: 12 maio 2014.

VALENTE, José Armando. Computadores e Conhecimento: repensando a educação. 2. ed. Campinas, SP: UNICAMP/NIED, 1998.

Submetido para avaliação em 21 de julho de 2015.

Aprovado para publicação em 07 de outubro de 2015.

Diego Vieira Braga - Universidade Católica de Pelotas, Pelotas, BR-RS. E-mail: diegho.braga@gmail.com Fabiane Villela Marroni - Universidade Católica de Pelotas, Pelotas, BR-RS. E-mail: fvmar@terra.com.br Patricia Pereira Franco - Universidade Católica de Pelotas, Pelotas, BR-RS. E-mail: patypfranco@yahoo.com.br 